and her face and neck were of a dull-purple colour. She remained deeply unconscious, and died on the morning of the 26th, at 1.30, the convulsive movements up to the last having been always most marked on the left side, which continued to be partially paralysed.

(To be concluded.)

\section{CASE OF \\ INTUSSUSCEPTION IN AN INFANT, ENDING FATALLY.}

By CHARLES J. CULLINGWORTH, M.R.C.S.,

SURGEON TO ST. MARY'S HOSPITAI FOR WOMEN AND CHILDERN, MANCHESTER.

ON the evening of the 27th July, 1874, Mr. and Mrs. Cleft Blackpool by train for their home in Manchester, bring. ing with them their baby, a fine healthy boy, fifteen weeks old. During their fortnight's sojourn at the seaside the child had been in his usual health, except that his stools had been somewhat curdy and of a greenish colour, which the mother attributed to the change of milk. Half an hour from the time of starting, the baby awoke from his sleep, and romited rather violently. Immediately after the attack his mother called the father's attention to a sudden change which had taken place in his appearance: he looked sunken and pale, "like death." During the remainder of the journey, which occupied two hours, he was restless and fretful, uttering, almost without cessation, an unusually weak, piteous cry. I saw him very soon after his arrival at home, and found him still collapsed, the surface was blanched, cold, and perspiring; the features sunk, and the pulse feeble. He closed his eyes for a few seconds, and then roused himself suddenly, as though in pain, with the weak, painful cry which his parents had before noticed. I told them that I feared a sudden displacement of the bowel had occurred. He was immediately wrapped in a small blanket wrung out of hot water, and then enveloped in a dry outer blanket and laid upon a couch. A teaspoonful of milk, to which a drop or two of brandy had been added, was ordered to be given every ten minutes. He died, however, without rallying, at 5.30 A.M. on the 28 th, not quite nine hours after the symptoms were first observed.

An examination of the body, twelve hours after death, revealed an invagination of the ileum, an inch and a quarter in length, situated at about its central portion, and lying deeply and posteriorly on the right side of the abdomen. The displacement was from above downwards. There were no external signs of inflammation, either in the part itself or in its neighbourhood. Wishful to preserve the specimen, I left the parts undisturbed, except that the inner fold was withdrawn (with the exercise of some force) to the extent of two or three lines, when it was observed to be distinctly congested, especially at its upper margin, where there had been some constriction. The stomach and upper part of the small intestine were a good deal distended with fatus, but were otherwise healthy. The canal had not been occluded by the displacement; for brandy and milk were found, apparently unchanged, in the parts below, and, indeed, the father assured me that a little had passed per anum.

\section{MEETING OF PUBLIC ANALYSTS AT CANNON-STREET HOTEL.}

A NOMEROUSLY attended meeting of public analysts took place at Cannon-street Hotel on Friday, August 7th. The chair was taken at a little after 4 o'clock, by Prof. Redwood, who opened the proceedings in a sensible and temperate speech. He pointed out that the meeting had been convened for the purpose of considering the Report of the Select Committee on the Adulteration of Food Act (1872), and of suggesting amendments to that Act. A printed draft of resolutions to be submitted to the meeting bad been sent round some days before, and to this the chairman referred. These resolutions were then put to the meeting seriatim.
Many verbal amendments were inserted, and some fresh resolutions were added, and ultimately, after full discussion, the great majority were carried almost unanimously.

The first discussion arose in regard to the proposed reference to Somerset-house Laboratory in disputed cases. Dr. Dupré pointed out that the certificate of a public analyst had very seldom been proved to be wrong, and that magistrates very rarely refused permission to have a second analysis made in the interest of the tradesman. If a court of referees must be established it would at any rate be necessary that the actual analyst should be present at the adjourned trial, and should give his evidence on oath. $\mathrm{Mr}$. Wanklyn took a similar view, asserting that a reference to Somerset House would be a reference from a higher to a lower authority. He argued that only one court of reference would be desirable-namely, a court consisting of the public analysts themselves. Mr. W. L. Scott, Mr. Allen, and Mr. Blyth also supported, in the main, this view of the case.

The third resolution had reference to the proposed examination, in doubtful cases, of candidates for the post of public analyst. Universal objection was expressed to the proposed selection of South Kensington as an examining centre, but it seemed to be generally admitted that some very loose appointments bad been made, and that cases must from time to time occur in which some definite test should be enforced. Dr. Tripe was warmly supported in his suggestion, that any such test should not be retrospective in its action, while Mr. Heisch proposed that a certificate of having worked two years in the laboratory of any competent analyst should be accepted as a qualification. $\mathrm{Mr}$. Bell urged that if a board of examiners were established, it should consist entirely of public analysts. It was ultimately settled that either a sufficient probation in an analytical laboratory or the passing of a suitable examination should be esteemed a qualification.

The vexed question of the facing of tea followed, and produced a lively discussion. Mr. Scott, Mr. Jones, Dr. Dupré, Mr. Burge, and Dr. Tripe objected to facing as an adulteration, and as such to any legalisation of it. On the other hand, Mr. Heisch, Mr. Wanklyn, Dr. Stevenson, Mr. Allen, and Mr. Estcourt urged that the facing of green tea, as usually practised, did not materially affect the quality or the value of the tea, and, at any rate, that it would be undesirable or even impossible to arrest the practice suddenly.

Mr. Wanklyn suggested that the ash should not be permitted to rise above 7 per cent., equal to about 2 per cent. of facing, and this suggestion was ultimately carried by a narrow majority.

The next resolution dealt with the question of mixtures. After one or two verbal alterations had been discussed, it was decided that such mixtures should be labeled, and that the percentage of the ingredients, under the name of which the mixture is sold, should be stated prominently on the label, any excess of foreign matter being considered an adulteration.

One or two resolutions referring to the duties of inspectors were then carried with little cpposition, and finally an Association of Public Analysts was formally established, with Professor Redwood for president, and a committee consisting, as we understood, of Messrs. Allen, Bernays, Dupré, Escourt, Hassall, Heisch, Stevenson, Wanklyn, and Wigner. Anotber meeting is to be held before long, and in the meantime the committee has undertaken the difficult task of preparing a definition of the term "adulteration," and some resolutions to be founded upon it.

We abstain from any comment in this place on the conclusinns reached by the new Association. Some of them we cordially endorse, while from others we differ ; but we congratulate the public analysts of England on the action they have taken, and wish them every success in their enterprise.

Donations, \&c., to Medical Charities.-The executors of the will of Mr. John Bagshawe, of Tideswell, have paid $\$ 500$ to the Devonshire Hospital, Buxton, and the General Infirmary, Sheffield, respectively. The Wolverhampton and Staffordshire General Hospital has become entitled to $\$ 500$ under the will of Miss Ann Stubbs, of Walsall. The Kent and Canterbury Hospital has received $\$ 46210$ s. from “J. M., on behalf of a friend." 